\title{
Thermodynamic properties of 1,3,5-trithiane derived from solid phase heat capacity measurements by adiabatic calorimetry and DSC measurements in the melting range
}

\author{
J.C. van Miltenburg* , P.J. van Ekeren \\ Faculty of Chemistry, Chemical Thermodynamics Group, Debye Institute, Utrecht University, Padualaan 8 , \\ $3584 \mathrm{CH}$ Utrecht, The Netherlands
}

Received 20 July 2001; accepted 20 August 2001

\begin{abstract}
The thermal properties of 1,3,5-trithiane were measured with adiabatic calorimetry and DSC between 15 and $500 \mathrm{~K}$. It was necessary to purify the compound even as the stated purity of the commercial product was $>99 \%$. The impurity present triggers a reaction at the melting point. The absolute entropy at $298.15 \mathrm{~K}$ was measured to be $(156.2 \pm 0.8) \mathrm{J} \mathrm{K}^{-1} \mathrm{~mol}^{-1}$, the enthalpy increment from 0 to $298.15 \mathrm{~K}$ is $(22936 \pm 100) \mathrm{J} \mathrm{mol}^{-1}$. The enthalpy of melting was found to be $(32.2 \pm 0.3) \mathrm{kJ}$ $\mathrm{mol}^{-1}$, the fusion temperature $488.4 \mathrm{~K}$. The molar heat capacity of the solid between 100 and $380 \mathrm{~K}$ can be described by a polynomial function $C_{p}=\left\{24.17+0.4004 T-9.9605 .10^{-5} T^{2}\right\} \mathrm{J} \mathrm{K}^{-1} \mathrm{~mol}^{-1}$, the standard deviation of this fit is $0.24 \mathrm{~J} \mathrm{~K}^{-1}$ $\mathrm{mol}^{-1}$. (C) 2002 Elsevier Science B.V. All rights reserved.
\end{abstract}

Keywords: 1,3,5-Trithiane; Calorimetry; DSC; Heat capacity

\section{Introduction}

Ring systems with different kind of atoms form an interesting group in organic chemistry. Oxygenand sulfur- containing molecules like 1,3,5-trioxane and 1,3,5-trithiane have been the subjects of several physical chemistry studies. In 1995 Dorofeeva and Gurvich published a survey of the work done on sulfur heterocyclic compounds [1]. Our group presented experimental molar heat capacity measurements of 1,3,5-triazine and 1,3,5-trioxane [2]. Vapour pressures and the derived enthalpy of vaporisation of $1,3,5-$ trithiane were published in 1983 [3]. Heat capacity

\footnotetext{
* Corresponding author. Tel.: +31-30-2532386; fax: +31-30-2533946.

E-mail address: miltenb@chem.uu.nl (J.C. van Miltenburg).
}

measurements made by DSC on 1,3,5-trithiane were published in the temperature range between 300 and $450 \mathrm{~K}$ [4]. This work reports on the thermal properties of 1,3,5-trithiane between $15 \mathrm{~K}$ and the melt. The aim of this work is to extend the knowledge of thermodynamic properties of the heterogeneous ring compounds.

\section{Experimental}

1,3,5-Trithiane was obtained from Fluka. The assay of this product was indicated as $>99 \%$. As other authors reported that at higher temperatures this compound showed solid-state polymerisation [5], and that the speed and amount of polymerisation probably depended on the impurities in the sample [6], the 
product was subjected to vacuum sublimation. The DSC measurements were performed using a Mettler Toledo DSC821 $1^{\mathrm{e}}$. The samples (approximately $6 \mathrm{mg}$ ) were encapsulated in aluminium crucibles. In all cases the heating and cooling rates were $5 \mathrm{~K} \mathrm{~min}^{-1}$. The adiabatic measurements were made with a sample of $0.65 \mathrm{~g}$. A new calorimeter, laboratory design "CAL8" was used [7]. This calorimeter is a scaled down version of CALV, the construction of which has been published in 1987 [8]; improvements in construction and data handling were presented in 1998 [9]. The same electronics are used for both calorimeters. The main difference is the use of a small sample vessel of about $1 \mathrm{~cm}^{3}$, this vessel fits closely into a sample holder, which is equipped with a heater and a $27 \Omega$ rhodium/iron thermometer. Oxford instruments calibrated the thermometer according to the ITS-90 scale [10]. The thermal contact between the vessel and the holder is very important. A small amount (about 1-2 mg) of Apiezon $N$ grease is used to improve the contact between the vessel and the holder. Corrections for the grease are made. However, as it is not always possible to remove the grease used in an earlier experiment completely from the holder, some inaccuracy is introduced. From several experiments with synthetic sapphire [11] and $n$-heptane [12], an inaccuracy in the specific heat measurement of $0.2 \%$ was found above $50 \mathrm{~K}$. Below this temperature deviations up to $3 \%$ were found. The measured enthalpy of fusion of $n$-heptane (four experiments; all within $0.1 \%$ ) deviated less than $0.1 \%$ from the literature value [12]. We estimate the overall inaccuracy of the heat capacity data and the derived properties to be $0.5 \%$.

\subsection{DSC experiments}

In Fig. 1a a H DSC curve obtained with trithiane "as received" is given. The figure shows three measuring curves. Curve A is the heating curve from 330 to $530 \mathrm{~K}$, curve $\mathrm{B}$ the cooling curve and curve $\mathrm{C}$ the second heating curve. In the first measurement (curve A) an exothermic effect occurred immediately after the melt. This effect was followed by an endothermic effect around $515 \mathrm{~K}$. Close to the melt a small endothermic effect took place. This curve has the same highlights as the curve given by Nadkarni and Schultz [5]. The exothermic effect however was not discussed in this article. The cooling curve B does show several thermal events, indicating that the solid does show two or three polymorphic forms. The second heating curve of the same sample (curve C) made under the same conditions with this sample showed hardly any exothermic effect. The melting peak shifted to lower temperature and the endothermic effect after the melt persisted. A purity analysis indicated a shift in purity from 99.5 in the first run to $98.5 \%$ in the second run.

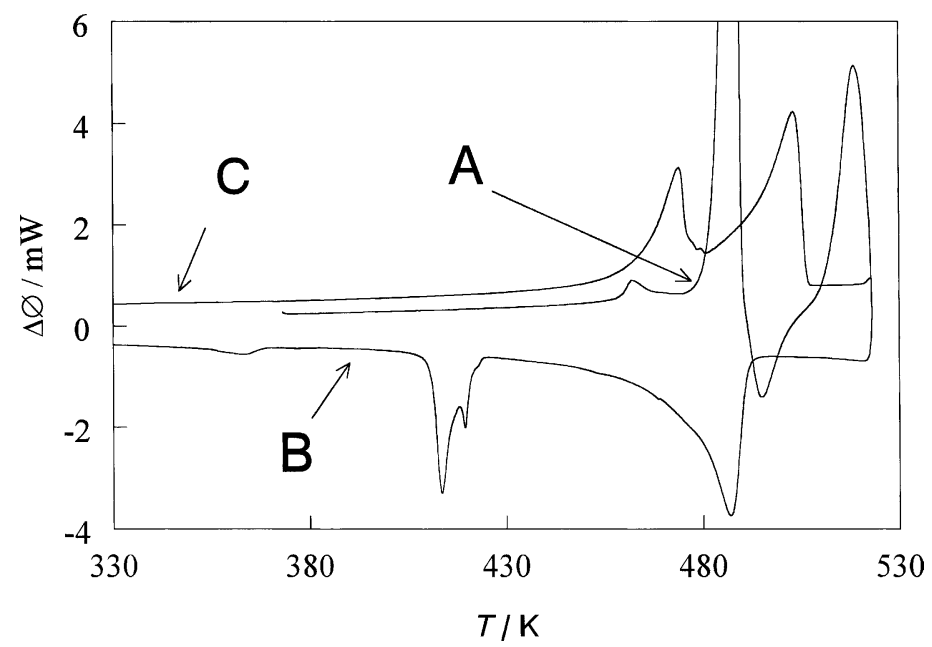

Fig. 1. DSC curve of $4.83 \mathrm{mg}$ of 1,3,5-trithiane "as received". (A) First heating curve; (B) cooling curve; (C) second heating curve. All measurements were made with a rate of $5 \mathrm{~K} \mathrm{~min}^{-1}$. 


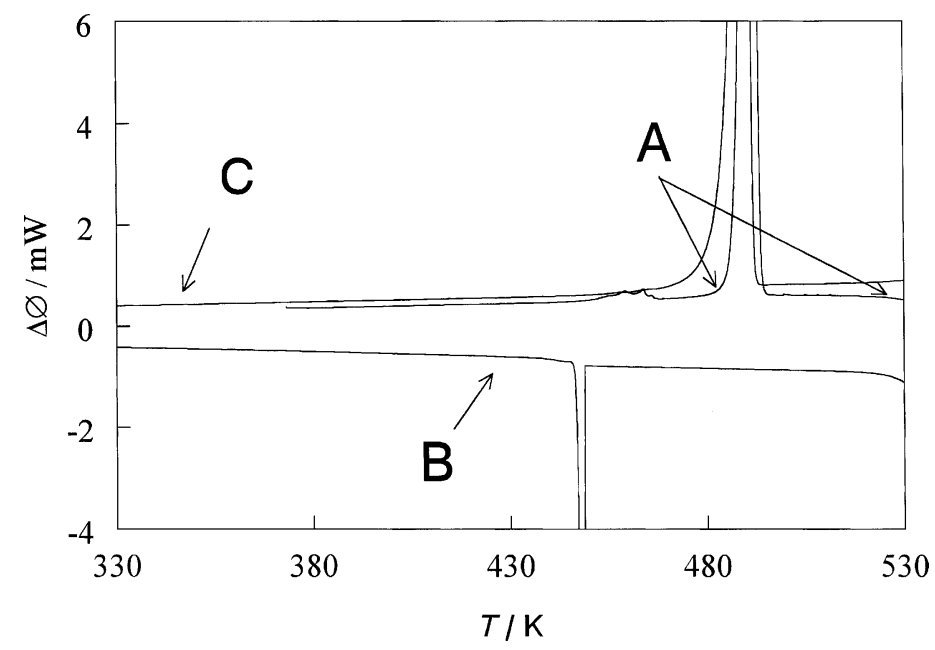

Fig. 2. DSC curve of $6.18 \mathrm{mg}$ of vacuum sublimated 1,3,5-trithiane. (A) First heating curve, note the exothermic tendency of the curve after the melt; (B) cooling curve with a sharp crystallization effect; (C) second heating curve. All measurements were made with a rate of $5 \mathrm{~K} \mathrm{~min}^{-1}$.

The DSC curve obtained from a measurement using a vacuum sublimated sample is given in Fig. 2. The indications $\mathrm{A}, \mathrm{B}$ and $\mathrm{C}$ in the figure have the same meaning as in Fig. 1. Obviously there is only a very small exothermic effect after the melt. The endothermic effect before the melt (around $463 \mathrm{~K}$ ) decreased significantly. The cooling curve B shows only one very sharp thermal effect. The second heating curve does indicate a slight increase in impurity, the onset temperature of the melt changed from 488.4 in the first run to $485.9 \mathrm{~K}$ in the second. In Table 1 the main aspects of the curves and the measured temperatures and enthalpies are collected. The enthalpy of fusion could only be calculated reliably from the experiments with the vacuum sublimated sample. In the measurement of the sample "as received" the exothermic effect makes it impossible to draw a base line. Repeating the measurement with the vacuum sublimated sample showed that after storing the product for about a week already a lower melting point and a lower enthalpy of fusion were measured. One sample cup with a vacuum sublimated sample was, after measuring it twice, stored for 4 months. Repeating the measurement showed no difference with the earlier second run. Measurement of a sample of the same vacuum sublimated batch, stored in a glass vessel for the same period of 4 months showed a marked increment of the endothermic effect at $463 \mathrm{~K}$ and a lower onset temperature. This is a strong indication that light is the cause of the formation of the impurity.

Table 1

Summary of DSC experiments

\begin{tabular}{|c|c|c|c|c|c|c|}
\hline $\begin{array}{l}\text { Sample treatment } \\
\text { and storage time }\end{array}$ & $\begin{array}{l}\text { Amount } \\
(\mathrm{mg})\end{array}$ & $\begin{array}{l}\text { Transition } \\
\text { temperature }(\mathrm{K})\end{array}$ & $\begin{array}{l}\text { Fusion onset } \\
\text { temperature }(\mathrm{K})\end{array}$ & $\begin{array}{l}\Delta H_{\text {trans }} \\
\left(\mathrm{J} \mathrm{mol}^{-1}\right)\end{array}$ & $\begin{array}{l}\Delta H_{\text {fus }} \\
\left(\mathrm{J} \mathrm{mol}^{-1}\right)\end{array}$ & Remarks \\
\hline As received & 5.66 & 463 & 481.9 & 760 & & Exothermic effect after melt \\
\hline As received & 4.83 & 462 & 483 & & & $\begin{array}{l}\text { Exothermic effect followed } \\
\text { by endothermic effect }\end{array}$ \\
\hline Freshly sublimated & 6.18 & 464 & 488.4 & 487 & 32200 & $\begin{array}{l}\text { Very small exothermic } \\
\text { effect between } 513 \\
\text { and } 523 \mathrm{~K}\end{array}$ \\
\hline Second measurement & 6.18 & 463 & 485.9 & & 30100 & No exothermic effect \\
\hline Sublimated, stored for 3 days & 11.21 & 462 & 487.3 & 335 & 31775 & Used for $\mathrm{C}_{p}$ measurement \\
\hline
\end{tabular}


Table 2

Experimental molar heat capacities of 1,3,5-trithiane in chronological order

\begin{tabular}{|c|c|c|c|c|c|c|c|}
\hline$T(\mathrm{~K})$ & $C_{p}\left(\mathrm{~J} \mathrm{~K}^{-1} \mathrm{~mol}^{-1}\right)$ & $T(\mathrm{~K})$ & $C_{p}\left(\mathrm{~J} \mathrm{~K}^{-1} \mathrm{~mol}^{-1}\right)$ & $T(\mathrm{~K})$ & $C_{p}\left(\mathrm{~J} \mathrm{~K}^{-1} \mathrm{~mol}^{-1}\right)$ & $T(\mathrm{~K})$ & $C_{p}\left(\mathrm{~J} \mathrm{~K}^{-1} \mathrm{~mol}^{-1}\right)$ \\
\hline Series 1 & & 232.75 & 111.95 & 34.54 & 22.60 & 361.13 & 155.66 \\
\hline 115.18 & 68.63 & 234.72 & 112.82 & Series 5 & & 365.23 & 156.92 \\
\hline 117.14 & 69.42 & 236.68 & 113.48 & 36.79 & 24.36 & 369.36 & 158.37 \\
\hline 119.91 & 70.51 & 238.64 & 113.86 & 39.11 & 27.35 & 373.50 & 159.69 \\
\hline 122.63 & 72.00 & 240.59 & 114.35 & 41.10 & 28.34 & 377.67 & 161.16 \\
\hline 125.31 & 72.95 & 242.52 & 115.01 & 43.37 & 30.43 & Series 7 & \\
\hline 127.97 & 73.62 & 244.44 & 116.26 & 45.71 & 32.21 & 300.57 & 135.61 \\
\hline 130.59 & 75.26 & 246.36 & 116.89 & 48.09 & 33.20 & 304.55 & 137.19 \\
\hline 133.19 & 75.83 & 248.27 & 117.46 & 50.49 & 36.15 & 308.51 & 138.64 \\
\hline 135.75 & 76.62 & 250.18 & 118.06 & 52.92 & 37.44 & 312.48 & 139.61 \\
\hline 138.29 & 77.52 & 252.08 & 118.65 & 55.39 & 39.39 & 316.45 & 140.99 \\
\hline 140.80 & 78.89 & 253.98 & 119.42 & 57.92 & 41.21 & 320.43 & 142.31 \\
\hline 143.30 & 79.37 & 255.89 & 119.71 & 60.47 & 42.81 & 324.41 & 143.68 \\
\hline 145.79 & 79.74 & 257.79 & 120.64 & 63.05 & 43.85 & 328.40 & 145.11 \\
\hline 148.23 & 81.89 & 259.68 & 121.40 & 65.67 & 45.76 & 332.39 & 146.39 \\
\hline 150.66 & 82.74 & 261.56 & 122.01 & 68.31 & 46.72 & 336.40 & 147.62 \\
\hline 153.06 & 83.53 & 263.44 & 122.79 & 70.97 & 48.64 & 340.41 & 149.01 \\
\hline 155.45 & 84.21 & 265.32 & 123.68 & 73.65 & 50.18 & 344.43 & 150.41 \\
\hline 157.82 & 84.97 & 267.19 & 124.23 & 76.36 & 51.34 & 348.47 & 151.57 \\
\hline 160.18 & 85.73 & 269.06 & 124.67 & 79.08 & 52.64 & 352.51 & 152.86 \\
\hline 162.52 & 86.68 & 270.93 & 125.55 & 81.82 & 54.11 & 356.56 & 153.85 \\
\hline 164.84 & 87.49 & 272.79 & 126.08 & 84.58 & 55.43 & 360.63 & 155.55 \\
\hline 167.15 & 88.38 & Series 2 & & 87.35 & 56.66 & 364.71 & 156.88 \\
\hline 169.44 & 89.25 & 10.97 & 0.42 & 90.13 & 58.29 & 368.81 & 158.15 \\
\hline 171.72 & 90.06 & 12.90 & 1.09 & 92.92 & 59.42 & 372.92 & 159.57 \\
\hline 173.98 & 90.91 & 14.75 & 2.48 & 95.72 & 60.85 & 377.05 & 161.08 \\
\hline 176.22 & 91.80 & 16.80 & 4.07 & 98.53 & 61.99 & 381.20 & 162.47 \\
\hline 178.46 & 92.65 & 19.03 & 6.34 & 101.35 & 63.04 & 385.37 & 163.69 \\
\hline 180.68 & 93.46 & 21.38 & 8.95 & 104.18 & 64.72 & Series 8 & \\
\hline 182.89 & 94.54 & 23.85 & 11.60 & 107.02 & 65.93 & 247.05 & 116.66 \\
\hline 185.09 & 95.30 & 26.46 & 14.23 & 109.87 & 66.80 & 250.98 & 117.96 \\
\hline 187.27 & 95.96 & 29.19 & 16.74 & 112.72 & 68.19 & 254.90 & 119.39 \\
\hline 189.44 & 96.39 & Series 3 & & 115.58 & 69.19 & 258.82 & 120.91 \\
\hline 191.60 & 96.83 & 11.38 & 0.52 & 118.45 & 70.40 & 262.74 & 122.35 \\
\hline 193.75 & 97.68 & 13.29 & 1.45 & 121.32 & 71.59 & 266.66 & 123.82 \\
\hline 195.89 & 98.54 & 15.24 & 2.99 & Series 6 & & 270.60 & 125.07 \\
\hline 198.02 & 99.49 & 17.45 & 4.74 & 293.29 & 133.39 & 274.53 & 126.62 \\
\hline 200.13 & 100.09 & 19.77 & 7.05 & 297.31 & 134.54 & 278.47 & 128.18 \\
\hline 202.24 & 100.92 & 22.21 & 9.74 & 301.27 & 136.13 & 282.41 & 129.56 \\
\hline 204.34 & 101.78 & 24.73 & 12.67 & 305.21 & 137.58 & 286.36 & 131.08 \\
\hline 206.42 & 102.47 & 27.39 & 15.07 & 309.14 & 138.64 & 290.32 & 132.26 \\
\hline 208.50 & 103.21 & 30.18 & 17.48 & 313.07 & 139.90 & 294.28 & 133.41 \\
\hline 210.57 & 103.95 & 33.09 & 21.09 & 317.00 & 141.37 & 298.25 & 135.46 \\
\hline 212.62 & 104.37 & Series 4 & & 320.95 & 142.58 & 302.22 & 135.97 \\
\hline 214.67 & 105.39 & 11.63 & 0.69 & 324.91 & 143.90 & 306.20 & 137.52 \\
\hline 216.72 & 106.12 & 13.17 & 1.61 & 328.87 & 145.15 & 310.19 & 138.74 \\
\hline 218.75 & 106.77 & 15.35 & 2.93 & 332.85 & 146.44 & 314.19 & 140.11 \\
\hline 220.77 & 107.69 & 17.73 & 5.19 & 336.84 & 147.75 & 318.20 & 141.08 \\
\hline 222.79 & 108.15 & 20.14 & 7.79 & 340.85 & 149.14 & 322.22 & 142.95 \\
\hline 224.80 & 108.81 & 22.71 & 10.63 & 344.88 & 150.25 & 326.25 & 144.31 \\
\hline 226.80 & 109.97 & 25.45 & 13.65 & 348.91 & 151.66 & 330.28 & 145.68 \\
\hline 228.79 & 110.55 & 28.33 & 16.33 & 352.96 & 153.10 & & \\
\hline 230.78 & 111.16 & 31.36 & 19.82 & 357.04 & 154.02 & & \\
\hline
\end{tabular}


The highest enthalpy of fusion measured was $233 \mathrm{~J} \mathrm{~g}^{-1}$, corresponding to $32.22 \mathrm{~kJ} \mathrm{~mol}^{-1}$ (molar mass $=138.28 \mathrm{~g} \mathrm{~mol}^{-1}$ ). The onset temperature of the fusion in this measurement was $488.4 \mathrm{~K}$. The enthalpy of fusion is much higher than the value reported in [5], which is $148 \mathrm{~J} \mathrm{~g}^{-1}$. Heat capacities were measured with samples of about $12 \mathrm{mg}$ between 305 and $525 \mathrm{~K}$. The measurements were performed by making three measuring runs, one with the empty sample cups; one with a sample of $22 \mathrm{mg}$ sapphire in one of the cups and a third with the sample. The values obtained are given in Table 4. The measurements with the sample were made in two series. Results of the first series, from 300 to $390 \mathrm{~K}$, correspond completely with the adiabatic calorimetry results. The second series, from 390 to $500 \mathrm{~K}$, was started after a period of about $2 \mathrm{~h}$ at $390 \mathrm{~K}$. The results do suggest that a slight exothermic effect is taken place, resulting in a lowering of the observed heat capacity.

\subsection{Adiabatic measurements}

$0.6518 \mathrm{~g}$ of vacuum sublimated 1,3,5-trithiane was loaded in a glove box in CAL8. The vessel was evacuated and about $1000 \mathrm{~Pa}$ of helium was admitted as heat exchange gas before closing. As we feared thermal decomposition at higher temperatures, measurements were started at low temperature. In Table 3 the temperature range, the heating and stabilisation periods and the mean heating rate for the different series are given. In the measuring range there was no indication of a phase transition. Temperature drifts in the stabilisation periods were within the normal range,

Table 3

Adiabatic heat capacity measurement series in chronological order ${ }^{\mathrm{a}}$

\begin{tabular}{clll}
\hline $\begin{array}{l}\text { Temperature } \\
\text { range }(\mathrm{K})\end{array}$ & $\begin{array}{l}\text { Stabilisation } \\
\text { time }(\mathrm{s})\end{array}$ & $\begin{array}{l}\text { Input } \\
\text { time }(\mathrm{s})\end{array}$ & $\begin{array}{l}\text { Mean heating } \\
\text { rate }\left(\mathrm{K} \mathrm{h}^{-1}\right)\end{array}$ \\
\hline $113-273$ & 500 & 560 & 6.8 \\
$11-29$ & 100 & 100 & 45 \\
$11-33$ & 100 & 100 & 48 \\
$11-34$ & 150 & 100 & 42 \\
$36-121$ & 400 & 400 & 12 \\
$290-377$ & 500 & 500 & 14 \\
$297-385$ & 350 & 500 & 17 \\
$244-330$ & 350 & 500 & 17 \\
\hline
\end{tabular}

\footnotetext{
${ }^{\mathrm{a}}$ The temperature range, the stabilisation and input times and the mean heating rate are given.
}

Table 4

Molar heat capacities of 1,3,5-trithiane measured by DSC

\begin{tabular}{llll}
\hline$T(\mathrm{~K})$ & $C_{p}\left(\mathrm{~J} \mathrm{~K}^{-1} \mathrm{~mol}^{-1}\right)$ & $T(\mathrm{~K})$ & $C_{p}\left(\mathrm{~J} \mathrm{~K}^{-1} \mathrm{~mol}^{-1}\right)$ \\
\hline 303.15 & 135.1 & 395 & 160.7 \\
308.15 & 137.1 & 400 & 161.2 \\
313.15 & 139.2 & 405 & 161.9 \\
318.15 & 141.0 & 410 & 162.7 \\
323.15 & 142.6 & 415 & 163.4 \\
328.15 & 144.7 & 420 & 164.5 \\
333.15 & 146.3 & 425 & 166.0 \\
338.15 & 148.1 & 430 & 167.5 \\
343.15 & 149.9 & 435 & 170.3 \\
348.15 & 152.1 & 440 & 174.3 \\
353.15 & 153.9 & 445 & 180.4 \\
358.15 & 155.7 & 450 & 189.3 \\
363.15 & 157.3 & 455 & 198.6 \\
368.15 & 158.7 & 460 & 210.5 \\
373.15 & 160.2 & 465 & 193.8 \\
378.15 & 161.9 & 470 & 194.5 \\
383.15 & 162.9 & 475 & 212.1 \\
388.15 & 164.5 & 480 & 267.1 \\
393.15 & 166.3 & 485 & 837 \\
& & 490 & 6867 \\
& & 495 & 247.1 \\
& & 500 & 237.6 \\
\hline
\end{tabular}

indicating that no measurable reaction took place. The mean molar heat capacities and the mean temperature of the interval over which the measurement was made are given in Table 2. In Table 5 the heat capacity, the entropy and enthalpy increments from $0 \mathrm{~K}$ are given at rounded temperatures. For the calculation of the entropy and enthalpy it was assumed that below $15 \mathrm{~K}$ the low temperature Debye relation, $C_{p}=$ $\alpha T^{3}$, could be applied. The table is extended to the liquid phase by using the DSC results. For this calculation it was assumed that the heat capacity as measured by adiabatic calorimetry between 300 and $380 \mathrm{~K}$ could be extrapolated linearly to the melting point. The function used is

$C_{p}=\{38.08+0.3255 T\} \mathrm{J} \mathrm{K}^{-1} \mathrm{~mol}^{-1}$

The heat capacity data are plotted in Fig. 3. In Fig. 4 the data for $T>300 \mathrm{~K}$ is given, together with the heat capacity values calculated from the DSC experiments. The drawn line in Fig. 4 represents the data we published in 1983 [4]. Between 100 and $380 \mathrm{~K}$ the molar heat capacity data can be represented within the 


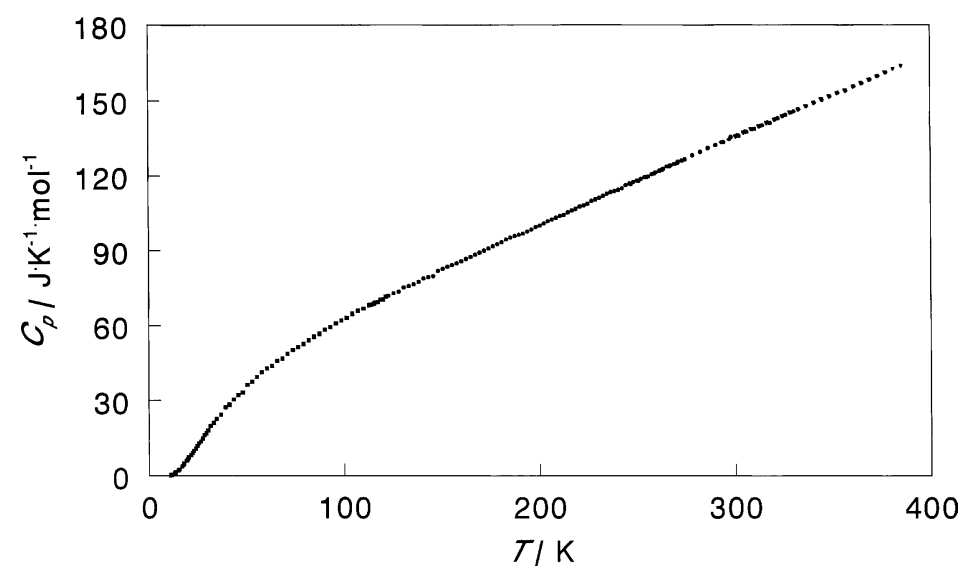

Fig. 3. Experimental molar heat capacities of 1,3,5-trithiane as measured by adiabatic calorimetry.

Table 5

Thermodynamic properties at selected temperatures for 1,3,5trithiane $^{\mathrm{a}}$

\begin{tabular}{|c|c|c|c|}
\hline$T(\mathrm{~K})$ & $C_{p, \mathrm{~m}}^{0}\left(\mathrm{~J} \mathrm{~K}^{-1} \mathrm{~mol}^{-1}\right)$ & $S_{\mathrm{m}}^{0}\left(\mathrm{~J} \mathrm{~K}^{-1} \mathrm{~mol}^{-1}\right)$ & $\begin{array}{l}H_{\mathrm{m}}^{0}(T)-H_{\mathrm{m}}^{0}(0) \\
\left(\mathrm{J} \mathrm{mol}^{-1}\right)\end{array}$ \\
\hline 15 & 2.746 & 0.9150 & 10.3 \\
\hline 20 & 7.534 & 2.349 & 35.7 \\
\hline 25 & 13.04 & 4.575 & 86.3 \\
\hline 30 & 17.31 & 7.269 & 160.4 \\
\hline 35 & 23.00 & 10.65 & 270.5 \\
\hline 40 & 27.81 & 13.80 & 388.5 \\
\hline 45 & 31.70 & 17.31 & 537.8 \\
\hline 50 & 35.67 & 20.80 & 703.7 \\
\hline 55 & 39.09 & 24.35 & 889.9 \\
\hline 60 & 42.54 & 27.90 & 1094 \\
\hline 65 & 45.31 & 31.31 & 1307 \\
\hline 70 & 47.96 & 34.75 & 1539 \\
\hline 75 & 50.76 & 38.16 & 1786 \\
\hline 80 & 53.13 & 41.50 & 2045 \\
\hline 85 & 55.63 & 44.80 & 2317 \\
\hline 90 & 58.23 & 48.04 & 2601 \\
\hline 95 & 60.51 & 51.24 & 2897 \\
\hline 100 & 62.53 & 54.40 & 3205 \\
\hline 105 & 65.10 & 57.50 & 3523 \\
\hline 110 & 66.85 & 60.57 & 3853 \\
\hline 120 & 70.56 & 66.57 & 4543 \\
\hline 130 & 75.09 & 72.39 & 5270 \\
\hline 140 & 78.15 & 78.02 & 6030 \\
\hline 150 & 82.75 & 83.59 & 6837 \\
\hline 160 & 85.65 & 88.99 & 7675 \\
\hline 170 & 89.40 & 94.25 & 8542 \\
\hline 180 & 93.19 & 99.54 & 9468 \\
\hline 190 & 96.86 & 104.59 & 10402 \\
\hline 200 & 100.04 & 109.70 & 11398 \\
\hline 210 & 103.75 & 114.67 & 12417 \\
\hline 220 & 107.35 & 119.58 & 13472 \\
\hline
\end{tabular}

Table 5 (Continued)

\begin{tabular}{llll}
\hline$T(\mathrm{~K})$ & $C_{p, \mathrm{~m}}^{0}\left(\mathrm{~J} \mathrm{~K}^{-1} \mathrm{~mol}^{-1}\right)$ & $S_{\mathrm{m}}^{0}\left(\mathrm{~J} \mathrm{~K}^{-1} \mathrm{~mol}^{-1}\right)$ & $\begin{array}{l}H_{\mathrm{m}}^{0}(T)-H_{\mathrm{m}}^{0}(0) \\
\left(\mathrm{J} \mathrm{mol}^{-1}\right)\end{array}$ \\
\hline 230 & 110.92 & 124.42 & 14562 \\
240 & 114.19 & 129.22 & 15690 \\
250 & 118.03 & 133.96 & 16852 \\
260 & 121.51 & 138.66 & 18048 \\
270 & 124.91 & 143.30 & 19278 \\
280 & 128.72 & 147.90 & 20543 \\
290 & 132.16 & 152.47 & 21847 \\
298.15 & 135.31 & 156.18 & 22936 \\
300 & 135.52 & 157.02 & 23187 \\
310 & 138.71 & 161.51 & 24558 \\
320 & 142.08 & 165.98 & 25965 \\
330 & 145.57 & 170.39 & 27400 \\
340 & 148.87 & 174.80 & 28877 \\
350 & 151.96 & 179.16 & 30381 \\
360 & 155.31 & 183.49 & 31918 \\
370 & 158.60 & 187.79 & 33486 \\
450 & 184.6 & 221.3 & 47209 \\
$488.4^{\mathrm{b}}$ & 197.1 & 236.9 & 54536 \\
$488.4^{\mathrm{c}}$ & 240.0 & 303.4 & 87036 \\
500 & 240.0 & 309.1 & 89820 \\
\hline
\end{tabular}

${ }^{a}$ Values in italic represent DSC data.

${ }^{\mathrm{b}}$ Represents solid.

${ }^{\mathrm{c}}$ Represents liquid.

experimental accuracy by a second order polynomial fit;

$$
\begin{aligned}
& C_{p}[100-380 \mathrm{~K}] \\
& \quad=\left\{24.17+0.4004 T-9.9605 .10^{-5} T^{2}\right\} \mathrm{JK}^{-1} \mathrm{~mol}^{-1}
\end{aligned}
$$

The standard deviation of this fit is $0.24 \mathrm{~J} \mathrm{~K}^{-1} \mathrm{~mol}^{-1}$. 


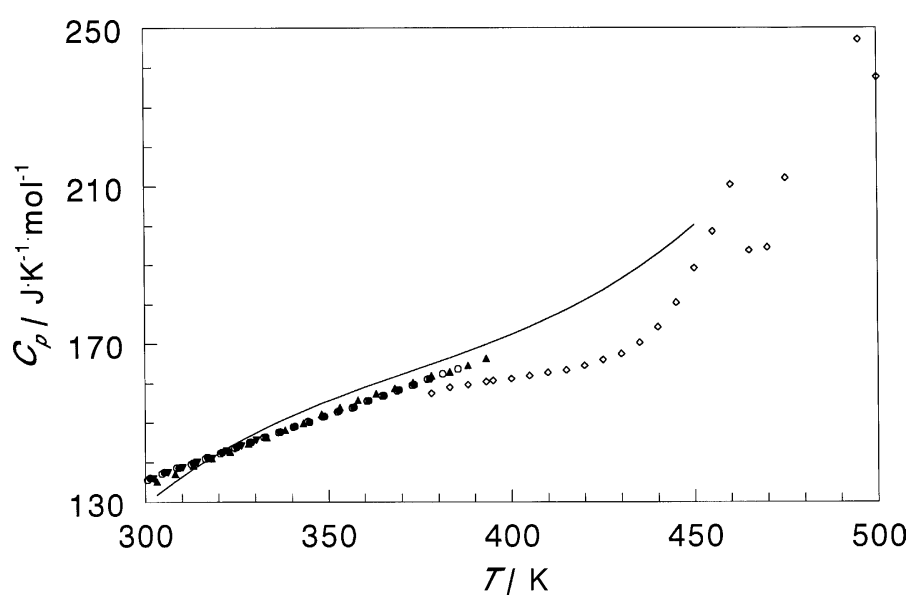

Fig. 4. High temperature molar heat capacity data of 1,3,5-trithiane. $(\bigcirc)$ and $(\mathbf{O})$ adiabatic measurements; $(\mathbf{\Delta})$ and $(\diamond)$ DSC measurement; (一) DSC measurements from 1983 [4].

\section{Discussion}

Heat capacities of 1,3,5-trithiane were measured between $15 \mathrm{~K}$ and the melt. The absolute entropy and the enthalpy increment from zero Kelvin were calculated. No phase transitions were encountered before the melt.

Two subjects need to be discussed. Firstly, Nadkarni and Schultz [5] assumed the thermal effect at $463 \mathrm{~K}$ to be caused by a solid-solid phase transition. We think that this effect is caused by the impurity in the sample and that it can be seen as a eutectic transition. The changing value of the effect as a function of purification supports this assumption. In the product "as received" we measured an effect of $5.5 \mathrm{~J} \mathrm{~g}^{-1}$, with an onset temperature of the melt of $481.9 \mathrm{~K}$. After sublimation this effect reduced to $3.5 \mathrm{~J} \mathrm{~g}^{-1}$ and the onset temperature of the melt increased to $488.4 \mathrm{~K}$. Nadkarni and Schultz [5] reported an effect of $10.8 \mathrm{~J} \mathrm{~g}^{-1}$, they did not report the onset temperature, but we estimate it to be $473.1 \mathrm{~K}$ from the plot given. Extrapolating these effects to a zero heat of transition results in a temperature of fusion of $494.4 \mathrm{~K}$. The $R$-squared value of this fit is 0.97 .

Secondly, the compound does show an exothermic effect immediately after the melt. However in the second run this effect has almost disappeared. It is more pronounced in samples that show a larger heat effect at $463 \mathrm{~K}$. We suggest that the impurity in the sample is involved in a reaction at the melting temperature. The impurity is then transformed in a product that does not trigger a reaction when the sample is heated again to that temperature.

\section{References}

[1] O.V. Dorofeeva, L.V. Gurvich, J. Phys. Chem. Ref. Data 24 (1995) 1351.

[2] M.J. van Bommel, J.C. van Miltenburg, A. Schuijff, J. Chem. Thermodyn. 20 (1988) 397.

[3] H.G.M. de Wit, J.C. van Miltenburg, C.G. de Kruif, J. Chem. Thermodyn. 15 (1983) 651.

[4] H.G.M. de Wit, J.C.A. Offringa, C.G. de Kruif, J.C. van Miltenburg, Thermochim. Acta 65 (1983) 43.

[5] V.M. Nadkarni, J.M. Schultz, J. Mater. Sci. 8 (1973) 525.

[6] J.E. Herz, V. Stannett, J. Polym. Sci. Polym. Lett. Ed. 4 (1966) 995.

[7] J.C. van Miltenburg, A.C.G. van Genderen, G.J.K. van den Berg, Thermochim. Acta, submitted for publication.

[8] J.C. van Miltenburg, G.J.K. van den Berg, M.J. van Bommel, J. Chem. Thermodyn. 19 (1987) 1129.

[9] J.C. van Miltenburg, A.C.G. van Genderen, G.J.K. van den Berg, Thermochim. Acta 319 (1998) 151.

[10] H. Preston-Thomas, Metrologia 27 (1990) 3.

[11] NBS Standard Reference Material 720, Washington DC, 1982.

[12] D.A. Archer, J. Phys. Chem. Ref. Data 22 (1993) 1441. 